\title{
Computational Analysis of Gas Phase Mixing in a Co-Fired Burner with Two Different Designs
}

\author{
J. Iqbal, S. Gao* \\ Department of Engineering, University of Leicester, Leicester, UK \\ Email: Jii1@le.ac.uk, ss32@le.ac.uk
}

Received January 2015

\begin{abstract}
The study of swirling jet combustor for biomass coal co-firing is of great interest for energy industry. The biomass co-firing can serve as a $\mathrm{NO}_{x}$ reduction method as well as the better use of renewable energy source. Large eddy simulation (LES) and RANS modelling have been performed with two different burner designs. Usually pulverized coal-biomass mixture enters the furnace along with primary air through primary pipe, and the secondary pipe provides necessary air and mixing for combustion. The improved model has three passages including primary, secondary and middle passage for swirling. The simulations on two geometries have been compared, and the aim is to design a better and improved burner model for better pre-combustion mixing in the biomass cofired furnace. The results from two-way and three-way geometry have been compared with each other as well as with the results from the furnace model used by Apte and Mahesh [8].
\end{abstract}

\section{Keywords}

Swirling Jet, Co-Firing, Biomass, Turbulence, LES

\section{Introduction}

During combustion process the fossil fuels release carbon dioxide, carbon monoxide, $\mathrm{SO}_{x}$ and $\mathrm{NO}_{x}$. Coal has different types and its chemical and physical properties of coal change with varying amount of carbon [1].

Biomass is one of the main renewable energy sources, having reasonable cost compared with other renewable sources. Biomass may be forestry material, agriculture waste, straw, municipal waste, sewage sludge etc. [3]. The biomass utilization can contribute in reducing $\mathrm{NO}_{x}, \mathrm{SO}_{x}, \mathrm{CO}_{2}$ and $\mathrm{CO}$. The biomass material has more volatility but low energy than hard coal, while a biomass-coal blend contains balanced volatility and energy. Usually biomass coal co-fired or retrofitted burners consist of primary air pipe conveying air fuel mixture, secondary air (swirled) pipe conveying additional air for turbulence and mixing [4]. In this project, the modified geometrical model consists of primary air pipe, secondary pipe and tertiary flow pipe. The air from secondary pipe helps to increase the turbulence mixing and produce wakes in the region away from the center line. The results from

\footnotetext{
${ }^{*}$ Corresponding author.
} 
two-way and three-way geometry have been compared with each other as well as with the results from the furnace model used by Apte and Mahesh [8], which is two-way model geometry. Different turnulence models and schemes have been used, and it is found that the three-way assembly is better than the two-way assembly for pre-combustion mixing. The geometrical models are shown schematically in Figure 1.

\section{Methodology}

The characteristics of fluid flow in the burner can be described by the fundamental conservation laws. This combines the continuity equation and momentum equation which are listed as follows:

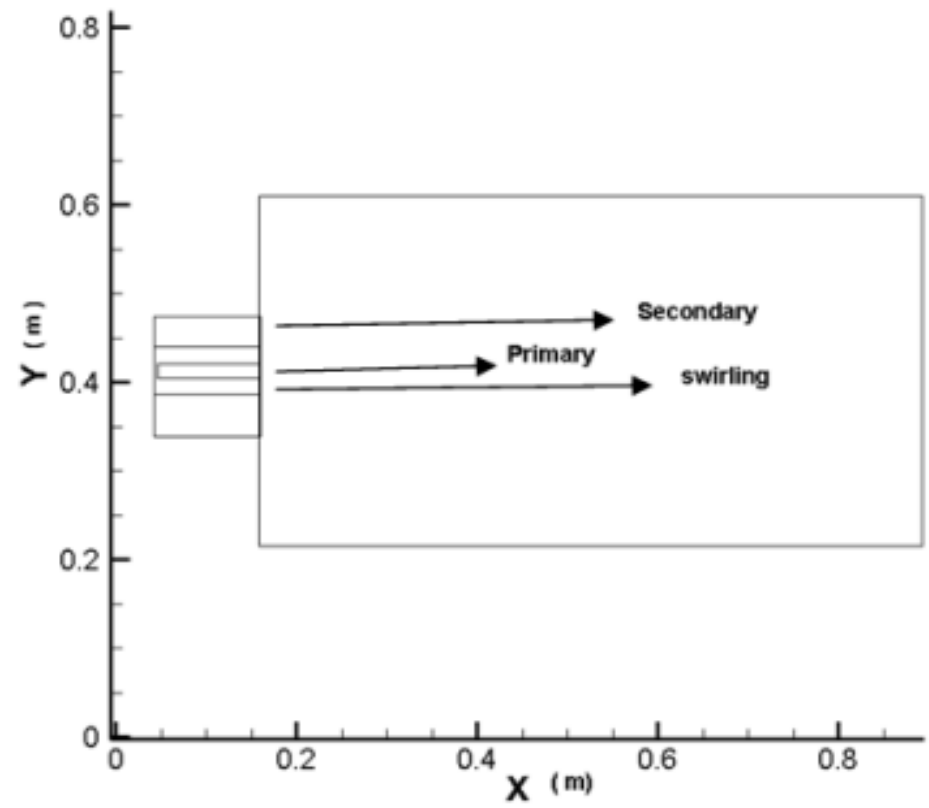

(a)

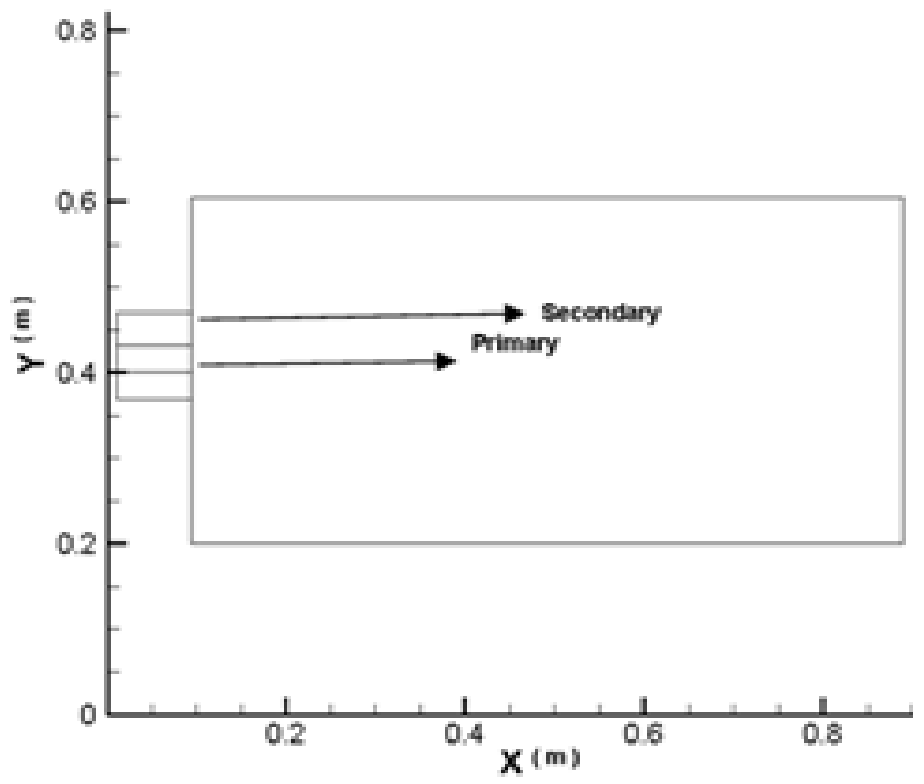

(b)

Figure 1. Schematic of biomass co-fired models. (a) Three-way assembly; (b) Two-way assembly. 


$$
\begin{gathered}
\frac{\partial \rho}{\partial t}+\nabla \cdot(\rho \vec{u})=0 \\
\frac{\partial(\rho \vec{u})}{\partial t}+\nabla \cdot(\rho \vec{u} \vec{u})=-\nabla p+\nabla \cdot \tau
\end{gathered}
$$

where

$$
\tau=-\eta\left(\nabla \vec{u}+(\nabla \vec{u})^{T}\right)+\frac{2}{3} \eta \vec{I} \nabla \cdot \vec{u}
$$

The burner geometry generation, meshing and calculation of the conservation of mass and momentum equations are carried out by using the commercial software package ICEMCFD and ANSYS Fluent.

Large eddy and RANS $k$-model simulations have been performed in this project to investigate the turbulence effects on the flow [2] [4]. It is well known that LES is a better tool for flows such as jet shear and wall jet impingement [7]. The LES scheme solves the filtered Navier-Stokes equation and can produce more useful information, e.g. instantaneous flow fluctuations, than the RANS viscous models. The leading flow parameters for the three-way assembly are given in Table 1. For the two-way assembly geometry, there is no tertiary entry, and the secondary is swirling flow.

The $2^{\text {nd }}$ order upwind scheme for flow and QUICK scheme for turbulence are selected with SIMPLE algorithm for the simulations. The turbulence simulation results are compared with each other and also with the simulation results from Apte and Mahesh [8].

\section{Results and Discussion}

The geometry from the reference [8] consists of two jets from primary and secondary annular pipe discharging into a huge cylinder. The effect of the jet velocity ratio shows the complexity of the isothermal models [4], while the new geometry has an additional annular pipe. It can be seen in Figure 2 that the flow in the new three-way geometry has better mixing than the two-way assembly from the reference of Apte and Mahesh [8]. The contours in Figure 2 show that the assembly with additional entry is more helpful for better pre-combustion mixing. The additional air produces additional turbulence and wake effects, and this additional air is also helpful to reburn the solid particles like coal/biomass in the burner [1].

Figure 3 and Figure 4 show the mean axial velocity and RMS of mean axial velocity variation with respect to the characteristic length for different assemblies; the swirling motion governs the flow to increase the rapid spreading and the reattachment of shear layers [8]. It can be seen that the axial velocity decreases with the characteristic length. The three-way assembly and two-way assembly have been compared with the results from the simulations of Apte and Mahesh [8] and the experimental work of Somerfield and Qiu [9]. In Figure 3 the mean axial velocity for the three-way assembly agrees well with the reference data. Comparison of radial and swirl velocity has also been made with the reference data [8] [9]. The swirl velocity decreases with the characteristic length as shown in the graphs. The radial velocity graphs show the different flow property than the swirling and axial velocity; here the radial velocity has the increased value at $X / R=0.8$ than the initial point $X / R=0.1$, slightly increase at $\mathrm{X} / \mathrm{R}=1.6$ and starts to decrease and becomes zero at the end point. The increasing and decreeing of the radial velocity produce the desired mixing in the combustor. The pressure is also a property of the moving fluid depending on the axial velocity, which decreases and increases with the axial velocity. The wall shear problems can also better be solved by using the three-way.

It is the pressure variation created in the fluid due to the kinetic energy fluctuations that produces the wake and mixing effects, which contribute positively to the mixing phenomena inside the furnace. Clearly, the improved three-way burner model has better mixing efficiency than the simple co-fired burner, mainly due to the addition of the new annular entry.

Table 1. Flow parameters for the three-way assembly.

\begin{tabular}{ccccc}
\hline Primary $(\mathrm{m} / \mathrm{sec})$ & Secondary $(\mathrm{m} / \mathrm{sec})$ & Tertiary $(\mathrm{m} / \mathrm{sec})$ & Temperature & Pressure $($ Pa) \\
\hline 15 & 10 & 18 & Not considered & Atmospheric \\
\hline
\end{tabular}




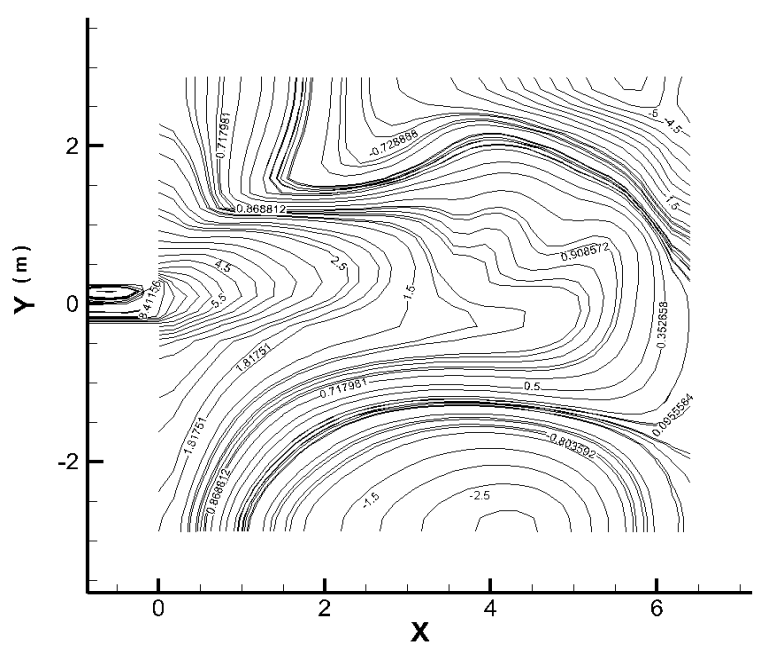

(a)

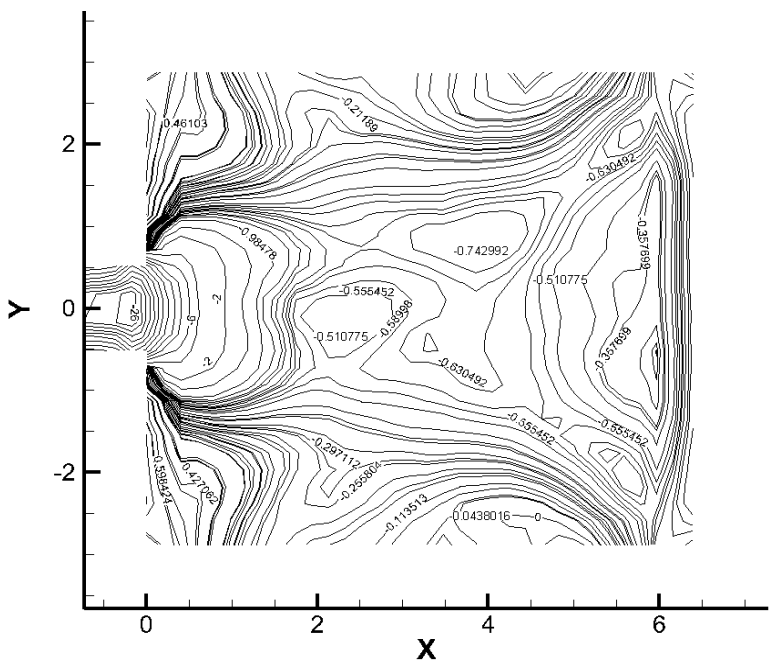

(b)

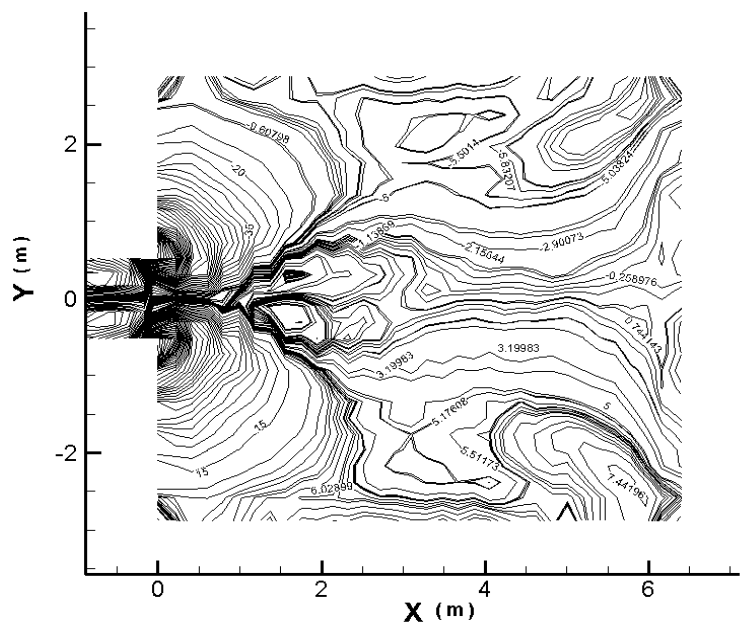

(c)

Figure 2. Axial velocity for (a) two-way geometry; (b) threeway geometry; (c) y-velocity for three-way geometry. 


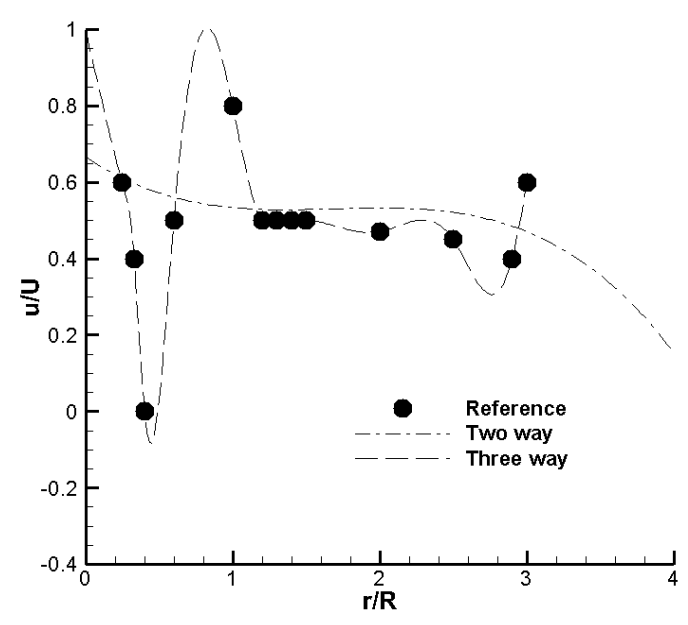

$\mathrm{X} / \mathrm{R}=0.1$
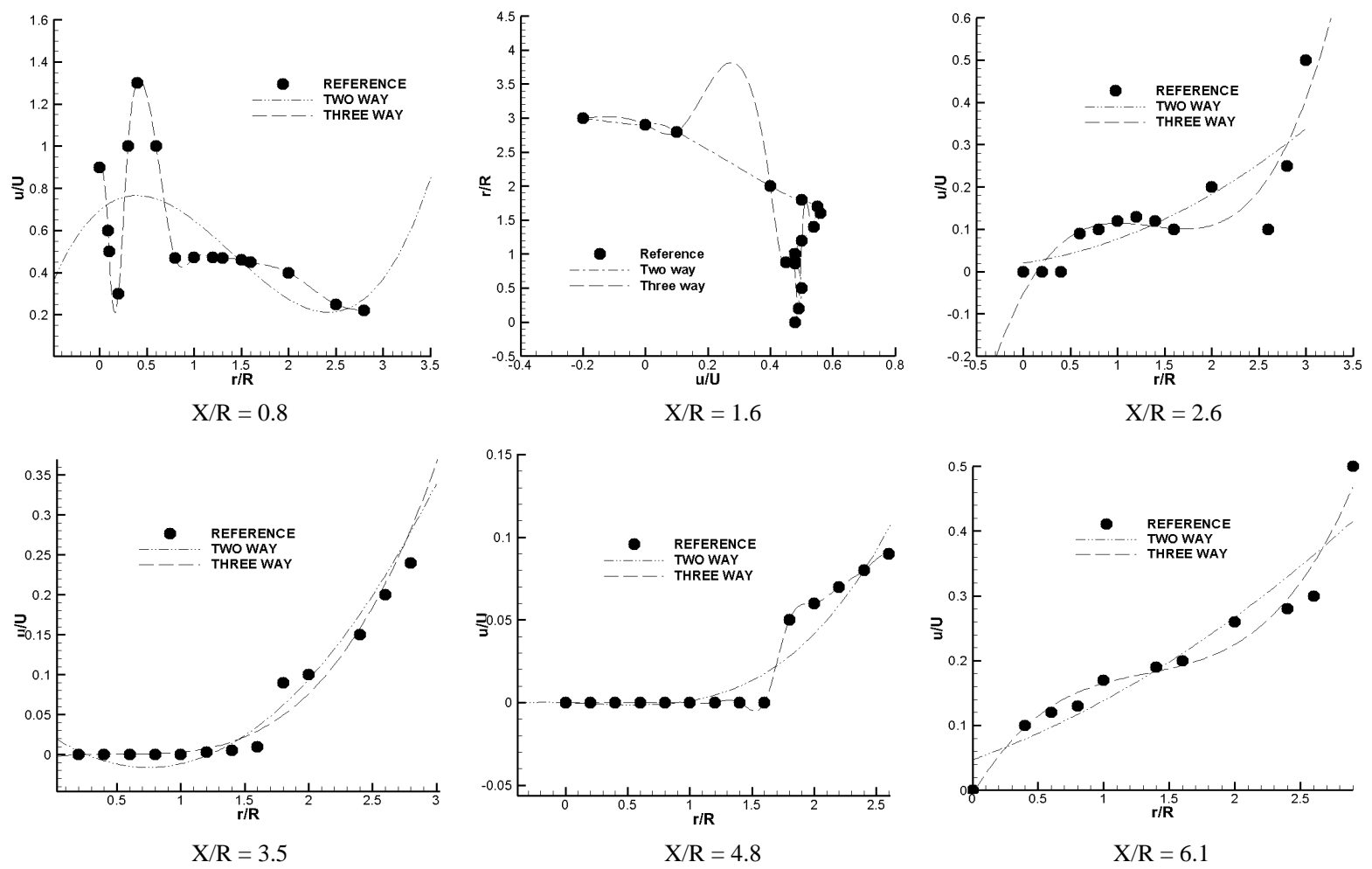

Figure 3. Axial velocity comparison between LES on two-way ( _.......), three-way (----) and experiment [9] ( $\bullet$ ) for swirling flow in combustor.

\section{Conclusion}

The physics of flow has been analyzed to understand the pre-combustion mixing behavior of air in two different burner geometries. The aim of the research is to design a better burner/furnace assembly for solid fuel biomass-coal co-firing. The additional un-swirled pipe as secondary entry increases the performance of the biomass coal co-fired burner because the solid fuel needs additional air for re-burning. The swirling flow produces turbulence, and the secondary pipe entry maintains the swirling for most of the time, which can produce wake effects in axial and radial directions. The efficient co-fired burner results in better use of the biomass as the main renewable energy source, and in turn it will result in the reduction of $\mathrm{SO}_{x}, \mathrm{NO}_{x}, \mathrm{CO}$ and $\mathrm{CO}_{2}$ from the emissions of coal fired power plants. The swirling and dynamic pressure effects mostly depend upon the axial velocity or 

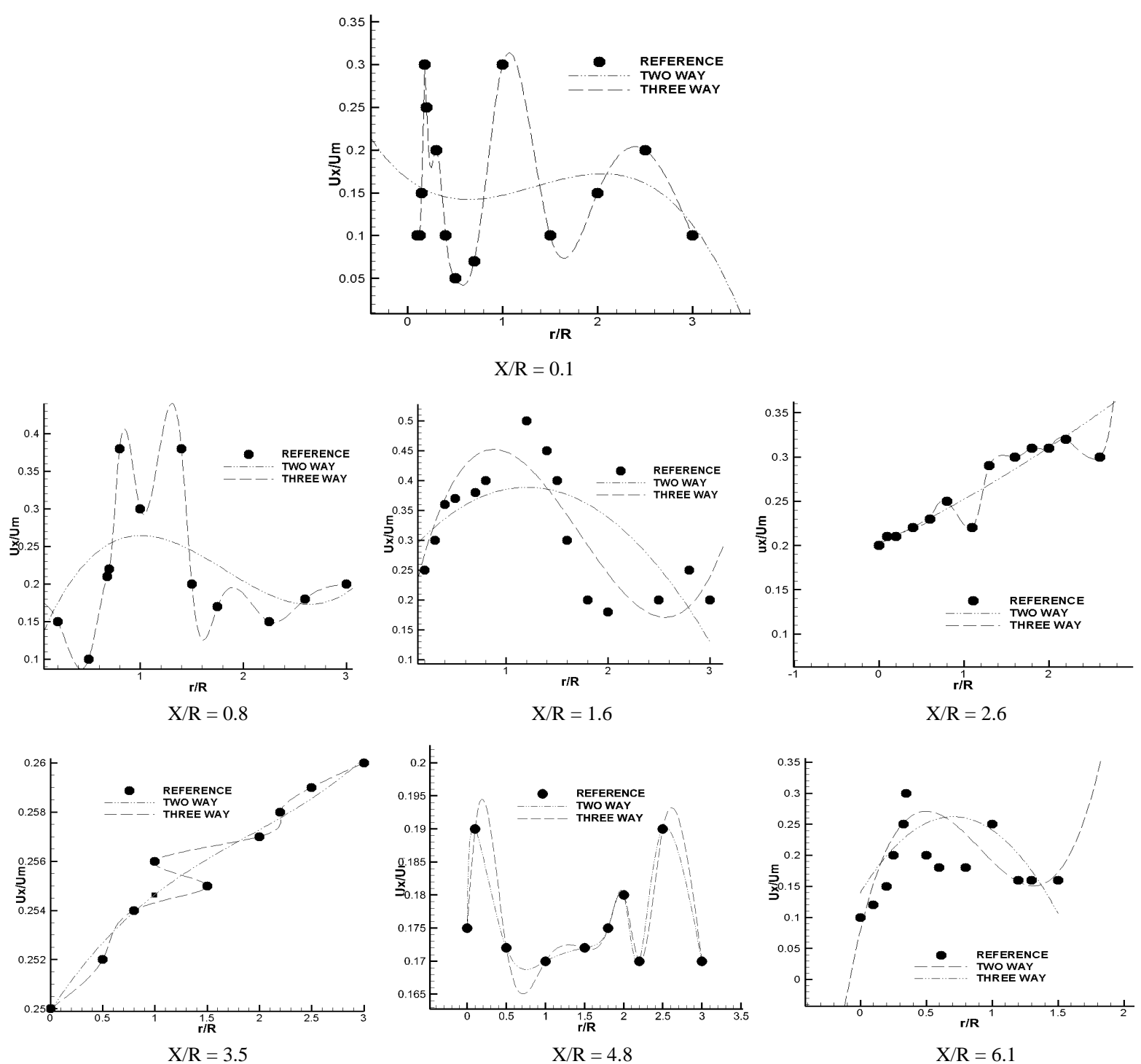

Figure 4. RMS of axial velocity comparison between LES on two-way ( _........), three-way (----) and experimental data [9] ( ) for swirling flow in combustor.

kinetic energy of the flow. The radial velocity variations are necessary for maintaining the efficient mixing in the burner.

\section{References}

[1] Aroussi, A., Iqbal, J., et al. (2008) Solid Fuel Biomass Co Firing with Coal. The 4th International Symposium on Hydrocarbon and Chemistry, Ghardaia, Algeria

[2] Glenn Research Centre (2009) Dynamic Pressure. www.grc.nasa.gov/WWW/K-12/airplane/dynpress.html

[3] Splithoff, H., Hein, K.R.G. (1998) Effect of Co-Combustion of Biomass on Emission in Pulverized Fuel Furnaces. Fuel Processing Technology, 54, 189-205. http://dx.doi.org/10.1016/S0378-3820(97)00069-6

[4] Sele, L., et al. (2004) Compressible Large Eddy Simulation of Turbulent Combustion in Complex Geometery on Unstructured Meshes. Combustion and Flame, 137, 489-505. http://dx.doi.org/10.1016/j.combustflame.2004.03.008

[5] Slack, M.D., et al. (2000) Advances in Cyclone Modelling Using Unstructured Grids. Trans IChemE, 78.

[6] Garcia, M., et al. (2006) LES of a Free Annular Swirling Jet-Dependence of Coherent Structure on a Pilot Jet and the Level of Swirl. International Journal of Heat and Fluid Flow, 27, 911-923. 
http://dx.doi.org/10.1016/j.ijheatfluidflow.2006.03.015

[7] Ahmed, S., et al. (2004) Experimental Investigation of Rectangular Slot Burner in the Presence of Cross Flow for Different Jet Velocity Ratios. 15th Australia Fluid Mechanics Centre Conferene, Sydney.

[8] Apte, S.V., Mahesh, K., et al. (2003) Large Eddy Simulation of Swirling Particle-Laden Flows in a Coaxial-Jet Combustor. Multiphase Flow, 1311-1331.

[9] Sommerfeld, M. and Qiu, H.H. (1991) Detailed Measurements in a Swirling Particulate Two-Phase Flow by a PhaseDoppler Anemometer. Int. J. Heat and Fluid Flow, 12, 20-28.

http://dx.doi.org/10.1016/j.ijheatfluidflow.2006.03.015 